\title{
Evaluation of the role of distal revascularization with interval ligation (DRIL) and revision using distal inflow (RUDI) in treatment of dialysis associated steal syndrome
}

\author{
Mohamed M Elwageh, $M D^{(a)}$; Ahmed H Elbarbary, $M D^{(a)}$; \\ Amro M AboRahma, $M D^{(a)}$; Mohamed Arafa $M S C^{(b)}$
}

(a) Department of Vascular Surgery, Tanta University.

(b) Department of General Surgery Department, Tanta University.

Objective: Dialysis-associated steal syndrome (DASS) is a complication that may occur in $>4 \%$ of patients with arteriovenous fistula. The best treatment method for this condition is up till now controversial.

Aim of the work: The purpose of this study was to evaluate two common procedures to treat this condition; Distal Revascularization with Interval Ligation (DRIL) or Revision Using Distal Inflow (RUDI) aiming at preservation of both the function of the fistula and the limb.

Patients and methods: Fourteen patients having native brachiocephalic or brachiobasilic hemodialysis AV fistula complicated by dialysis associated steal syndrome (DASS), were randomly divided according to treatment method into DRIL and RUDI groups with 7 patients in each group. Patients with proximal or distal arterial disease and those with low-flow steal were excluded. Short term access patency and limb salvage were set as primary endpoints. In all patients great saphenous vein was harvested from the thigh. Early post-procedural follow up and mid-term follow up were after one and three months.

Results: From November 2011 to March 2013, 14 patients presented with (DASS). In DRIL group (7 patients), the mean age was 49.2 years, 4 females and 4 diabetics while in RUDI group (7 patients), the mean age was 52.3 years, 5 females and 7 diabetics. All fistulas were brachiocephalic and only one was brachiobasilic AVF in DRIL group. All patients in both groups presented with pain, pallor, coldness and cyanosis of the hand. Stage III DASS (rest pain) was present in 2 cases of each group, whereas Stage IV small superficial ulcers were present in 3 vs 4 and digital gangrene in 2 vs. 1 in DRIL vs. RUDI respectively. In group 1 (DRIL) technique; 5 patients $(71.4 \%)$ had marked improvement of pain, cyanosis, capillary refill and coldness. Pallor improved in all cases. Distal pulses returned in 4 patients, remained weak in one patient and failed to return in 2 (28.6\%). Closure of the access was necessary in 2 patients due to infection in one and due to risk of limb loss in the other; access patency was (71.4\%) and limb salvage was (100\%). In RUDI cases, pain, hand coldness, pallor and cyanosis greatly improved in all cases post-operatively. Distal pulses and capillary refill returned and became comparable to the healthy side in 6 patients (85.7\%). Limb salvage and access patency were achieved in all cases (100\%).

Conclusion: RUDI procedure incorporates most of the advantages of other access and hand-preserving procedures. In contrast to DRIL procedure, it is the fistula that is placed at risk by ligation and revascularization, not the native arterial supply to the ischemic hand. RUDI may become the procedure of choice for patients with dialysis-associated steal syndrome after a brachial artery-based arteriovenous fistula.

Key words: Steal syndrome, DASS, AV fistula, DRIL, RUDI. 


\section{Introduction:}

Arteriovenous fistulae in the arm are commonly used for hemodialysis in endstage renal disease. All fistulae shunt blood away from the distal arm, and physiological steal (reversed flow in the artery distal to the arteriovenous fistulae) can occur in $70 \%$ of radiocephalic fistulae and $90 \%$ of brachial artery based fistulae. However, symptoms of hand ischemia (pain, pallor, cyanosis, paraesthesia, ulcers or gangrene) only occur in $1-2 \%$ of radiocephalic fistulae and $5-10 \%$ of brachial artery based fistulae. ${ }^{1-5}$

Any vascular disease that affects the proximal or distal arteries (e.g. atherosclerosis, vasculitis, Buerger's disease) can reduce flow to cause symptoms. The risk factors for ischemic steal syndrome include diabetes mellitus, peripheral artery disease, age greater than 60 years, women, upper arm versus lower arm fistulae, multiple operations in the same limb, and the use of PTFE grafts. ${ }^{4,6-9}$ These factors presumably relate to increased or more diffuse arteriosclerosis of the arteries in the forearm and hand, and poor development of collaterals. ${ }^{10}$

Several techniques have been used for managing dialysis associated steal syndrome (DASS) Figure (1), including banding, access ligation, distal revascularization with interval ligation (DRIL), 11 revision using distal inflow (RUDI), and proximalization of the arterial inflow (PAI). ${ }^{12}$ None of these techniques have been proven to be the method of choice. In distal radiocephalic fistulae, simple ligation of the distal radial artery is often used to eliminate retrograde flow into the AVF. ${ }^{13}$

\section{Patients and methods}

Study design: This prospective randomized study was conducted on fourteen patients presented with dialysis associated steal syndrome (DASS) after native brachial arterybased hemodialysis arteriovenous fistula admitted to vascular surgery unit, department of general surgery, Tanta University Hospitals during the period from November 2011 to March 2013. Patients were divided randomly between 2 groups : group one 7 patients who had distal revascularization interval ligation (DRIL) technique; and group two 7 patients who had revision using distal inflow (RUDI) technique. Randomization was done by allocation of cases presented by odd numbers to group 1 (DRIL) and cases presented by even numbers to group 2 (RUDI).

Inclusion criteria:

- Dialysis associated steal syndrome presented by rest pain, ulcer, necrosis or gangrene due to native brachiocephalic or brachiobasilic dialysis AV fistula.

Exclusion criteria:

- Patients with proximal or distal arterial disease.

- Patients with low-flow steal syndrome. Study endpoints:

- Short term access patency and limb salvage.

Before participation in the study a written informed consent was taken from each patient according to the ethical committee arrangement measures of the faculty.

Outcome variables: A detailed history including demographic data, continuous medical diseases as diabetes mellitus, hypertension and ischemic heart disease. Duration, type and site of AV fistula; presenting signs and symptoms as pain, coldness, numbness, trophic changes, necrosis and digital gangrene. Check up of radial and ulnar pulses before and after compressing the anastomotic site to record the change in pulse volume and force and whether radial and/ or ulnar pulses return or not. The degree of ischemic steal was recorded in each patient according to the following Table(1).

Duplex study was performed for the affected limb to evaluate; venous outflow volume, state of arterial tree in the upper limb proximal and distal to the fistula and augmentation of flow after compression of anastomotic site. CT arteriography of the affected arm was done when proximal or distal arterial lesions were suspected by duplex or when no return of radial or ulnar pulses after compression of anastomotic site.

Operative procedure: Under general anaesthesia a skin incision was done just above the cubital fossa for proximal 
anastomosis and another one in the forearm for distal (radial or ulnar) anastomosis, skeletonization of brachial artery and venous side of fistula from proximal incision and distal arteries(radial or ulnar) from distal incision. (1) In DRIL procedure, Figure (2) the brachial artery just below the fistula was ligated to prevent reversal of flow in the distal artery, and a bypass graft was placed from the brachial artery well above the fistula $(3-5 \mathrm{~cm})$ to the dominant artery (radial or ulnar) distal to the fistula. (2) In RUDI, Figure (2), ligation of the venous limb of the fistula at its origin and creation of a bypass to the fistula from one of the more distal forearm arteries, distal anastomosis first then proximal anastomosis was done. In all patients the graft was from the great saphenous vein harvested from the thigh.

Follow-up: Patients were subjected to early clinical follow up and mid-term clinical and duplex follow up after one and three months; to quantify blood flow in fistula and evaluate reversal of blood flow in artery distal to fistula.

\section{Results:}

Total number of patients in both groups was 14 with 7 patients in each group. The mean age for DRIL group was 49.2 years and that of RUDI group was 52.3 years. In DRIL group there were 3 males and 4 females, while in RUDI group there were 2 males and 5 females. Interval from AVF creation to intervention (DRIL or RUDI) had a mean of 13 months (ranging from 0 to 45 months). Hypertension was present in 8 cases 4 in each group, diabetes mellitus in 11 cases 4 in group (1) and 7 in group (2). All fistulae were brachiocephalic and only one was brachiobasilic AVF in group (1). All fistulae were functioning with palpable thrill and audible murmur at time of first examination. Clinical presentation and staging of patients was described in Tables $(\mathbf{2 , 3})$.

Pain, pallor, cyanosis and coldness were constant features in all patients. Motor and sensory weakness were observed during examination in 5 patients ; 3 in group (1) and 2 in group (2). Radial pulse was not palpable in 10 cases 5 in each group and weaker than the contra-lateral palpable radial pulse in the remaining 4 cases. Compression on the site of anastomosis augments pulse force in the weak group and rendered the radial pulse palpable in 10 cases $(71.43 \%)$ this finding was also confirmed by Doppler examination.

Preoperative CT angiography was done in 4 cases to confirm or exclude associated concomitant arterial occlusive disease suspected by previous duplex study. No arterial stenosis proximal or distal was revealed in these cases. Two more patients who did not yet start dialysis did not undergo angiography because of concerns of nephrotoxicity.

Post-operative outcome:

I. Clinical outcome Table (3): In patients who had correction of steal syndrome by DRIL technique; marked improvement of pain, cyanosis, capillary refill and coldness was observed in 5 patients $(71.4 \%)$, the other $2(28.6 \%)$ had no or minimal improvement. Hand pallor improved in all cases, however in 2 cases $(28.6 \%)$ cyanosis was reported during dialysis sessions. Distal pulses returned in four patients, remained weak in one patient and failed to return in the remaining $2(28.6 \%)$. In 2 patients (stage IV)(28.6\%) amputation of gangrenous digits was performed without significant wound complications. A closure of the access was necessary in 2 patients due to infection in one and due to failure of improvement of manifestations and risk of limb loss in the other; so access patency here was only $(71.4 \%)$ trying for limb salvage which was $(100 \%)$.

In cases managed by RUDI technique the results were much better where pain, hand coldness, pallor and cyanosis greatly improved in all cases post-operatively. Distal pulses returned and became comparable to the healthy side in 6 patients $(85.7 \%)$ and weaker than the healthy side in one patient, capillary refill improved to normal in 6 patients $(85.7 \%)$ and delayed in 1 patient (14.3\%). No early postoperative complications happened. In one patient (stage IV)(14.3\%) an amputation of gangrenous distal two phalanges of medial 3 fingers of left hand was performed without 
wound complications. Limb salvage and access patency were achieved in all cases $(100 \%)$.

II. Clinical follow-up: The mean followup period was 75 days; range (35-90 days). Amputation of gangrenous digits was performed for stage IV patients in both groups without significant wound complications and healing of stumps occurred after a mean period of 40 days in DRIL group and 43 days in RUDI group. Healing of ulcers and trophic lesions Figures $(\mathbf{4 , 5})$ was observed in all cases after a mean period of 29 days in group (1) and 21 days in group (2); except in one case of group (1) in which absence of healing after 3 weeks together with lack of improvement of symptoms and signs necessitated ligation of fistula.

III. Duplex results : There was a reduction in mean venous (fistula) outflow velocity and mean vein diameter in face of improved proximal (brachial) and distal artery flow velocity and wave patterns.

\section{Discussion:}

Storey et al. in 1969 first described steal syndrome associated with vascular accesses for dialysis, secondary to a Brescia-Cimino fistula between the radial artery and the distal cephalic vein. ${ }^{14,15}$ In this type of fistula approximately $75 \%$ of the blood flow is supplied by the proximal radial artery, but $25 \%$ comes from a patent ulnar artery via the distal radial artery and palmar arch. ${ }^{16}$ In elbow fistulae, the periarticular arterial collaterals have the same impact. ${ }^{1}$

Physiologic steal (stage I) with retrograde flow in the arm artery distal to the fistula is common after the creation of a fistula because of the low vascular resistance of the venous outflow compared to the higher peripheral arterial resistance. ${ }^{17,18}$ The development and dilatation of collateral arteries from the proximal inflow artery over months following creation of the fistula increases blood flow to the hand ${ }^{17}$ compensating for enhanced systolic AV flow and also for diastolic retrograde inflow into the fistula. ${ }^{18}$ Another contributing factor is hypotension which is a common event during a dialysis treatment which tends to lower venous return, reducing cardiac output and lowering the perfusion pressure in the fistula outflow artery and collaterals that supply the hand ${ }^{18}$ and may subsequently result in symptoms of steal only during periods of hypoperfusion related to hypotension ${ }^{19}$ (stage II).

Pathological steal with continuous ischemic symptoms can occur because of proximal inflow disease, reduced collateral flow to the hand, or distal outflow obstruction. These all disturb the normal compensatory mechanisms (peripheral vasodilatation and increased collateral flow) to preserve perfusion to the distal arm. ${ }^{10}$ Arterial stenosis upstream of the anastomosis prevents the necessary flow increase in the feeding artery; severe peripheral arterial occlusive disease (PAOD) or vasculitis enhance the resistance of distal arteries and simultaneously impair the function of natural collaterals. ${ }^{18}$ Instead of a steal syndrome stage I (also named steal phenomenon) or II during dialysis or exertion, the more advanced stages III or IV develop, with clinical signs of peripheral ischaemia. Under these conditions, during diastole virtually all blood coming from the collaterals is drained into the access. ${ }^{20}$

Several diagnostic tools, including measurement of systolic pressure index (SPI), finger-arm pressure index, digital plethysmography with oxymetry, and pulsed Doppler, have been proposed to evaluate hemodynamic parameters distal to AVF to identify patients at risk for development of symptomatic steal syndrome. $5,21-24$ Although these techniques can detect a decrease in pressure and digital perfusion that improves after compression of the AVF, they are poor predictors of the risk of hand ischemia. ${ }^{25}$ Thus careful clinical examination is important to determine the severity of symptoms and thus the need for prompt surgical treatment to avoid the appearance of irreversible neurologic sequelae or extensive trophic manifestations that can require major amputation. Appearance of neurologic symptoms can mimic carpal tunnel syndrome, which can delay diagnosis and lead to unwarranted intervention for decompression 


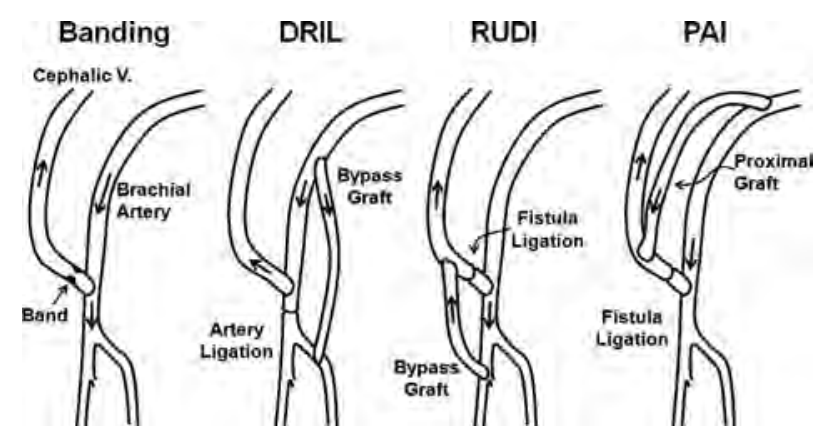

Figure (1): Several methods to manage DASS; (DRIL, distal revascularization, interval ligation; $R U D I$, revision using distal inflow; PAI, proximal arterial inflow graft. ${ }^{13}$ )
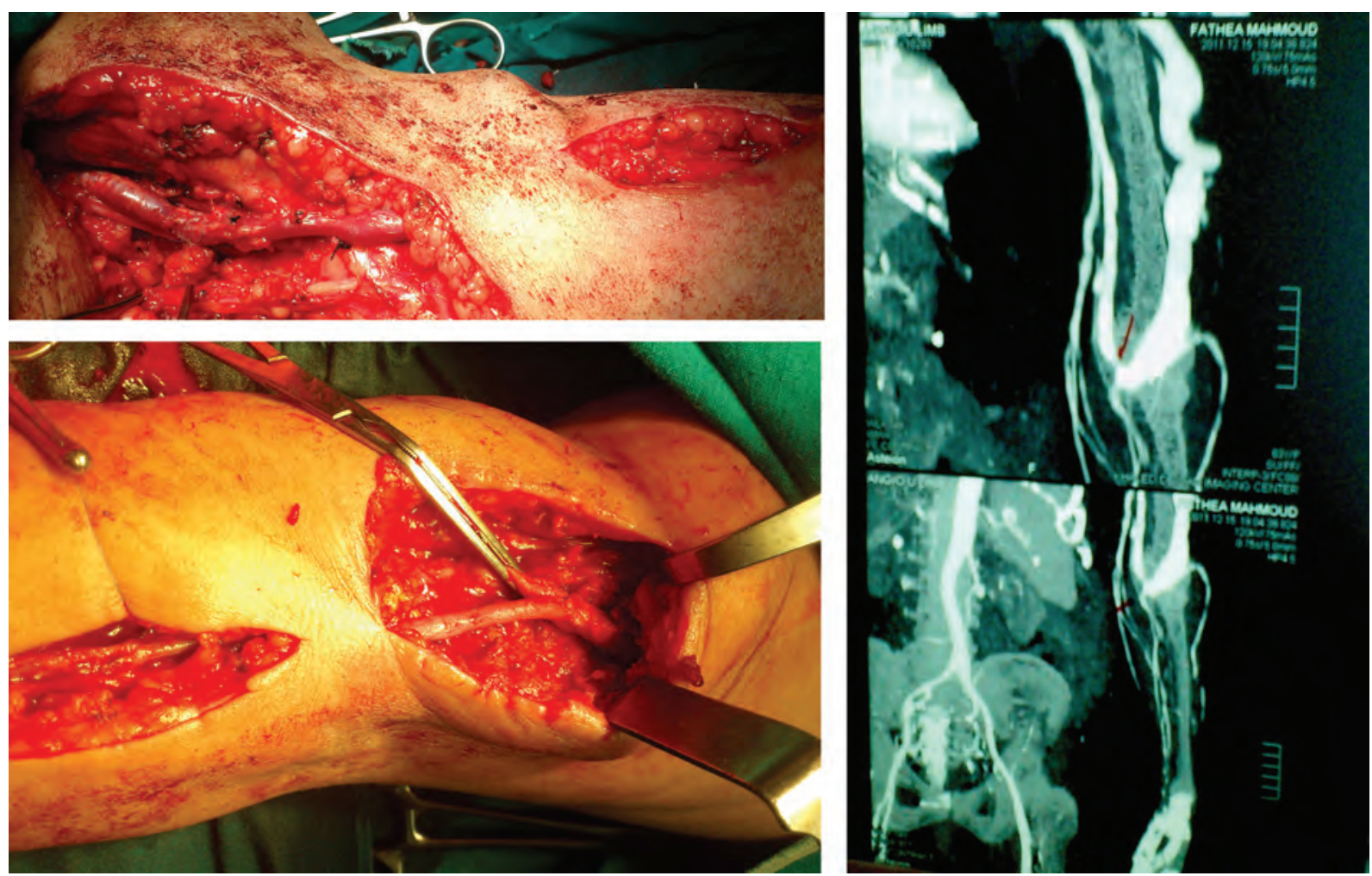

Figures (2,3): 2) above DRIL , below RUDI 3) CT angiography in DASS case with no proximal or distal arterial lesion.
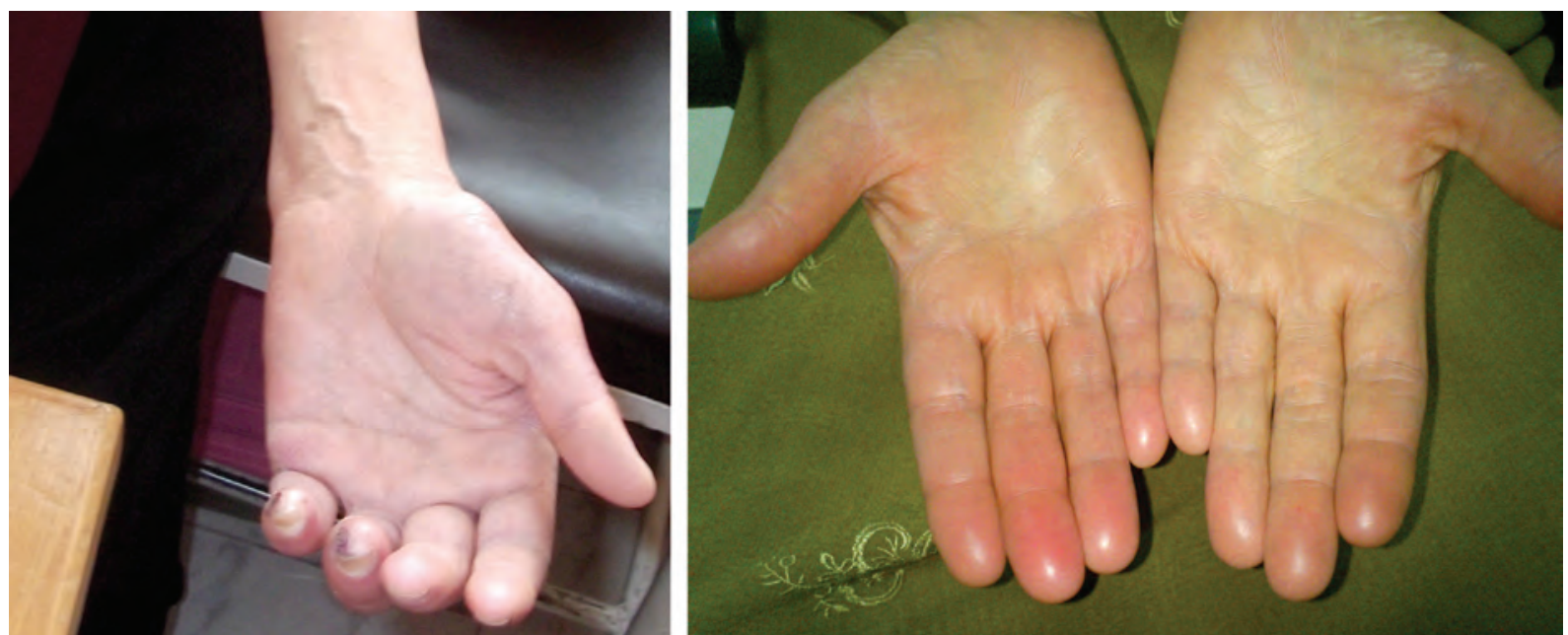

Figures (4,5): A case of trophic ulcers healed after RUDI. 
Table 1: Classification of dialysis associated steal syndrome. ${ }^{1}$

\begin{tabular}{|l|l|}
\hline Stage I & $\begin{array}{l}\text { No pain; pale, blue and/or cold hand (Retrograde diastolic flow without complaints); } \\
\text { steal phenomenon }\end{array}$ \\
\hline Stage II & Pain on exertion and/or during haemodialysis \\
\hline Stage III & Rest pain \\
\hline Stage IV & Ulceration/necrosis/gangrene \\
\hline
\end{tabular}

Table 2: Clinical staging of study cases at time of presentation.

\begin{tabular}{|l|l|l|}
\hline \multirow{2}{*}{ Clinical stage } & DRIL & RUDI \\
\cline { 2 - 3 } & No. (\%) & No. (\%) \\
\hline Stage III (Rest pain): & $2 / 7(28.57 \%)$ & $2 / 7(28.57 \%)$ \\
\hline Stage IV: & & \\
a)Superficial ulcer/ Necrosis & $3(42.86 \%)$ & $4(57.14 \%)$ \\
b)Digital gangrene & $2(28.57 \%)$ & $1(14.28 \%)$ \\
\hline
\end{tabular}

Table 3: Clinical examination of the patients before and after management.

\begin{tabular}{|c|c|c|c|c|}
\hline & DRIL & \multicolumn{3}{|c|}{ RUDI } \\
\hline & Preoperative & $\begin{array}{c}\text { Early } \\
\text { postoperative }\end{array}$ & Preoperative & \begin{tabular}{|c|} 
Early \\
postoperative
\end{tabular} \\
\hline & $\mathrm{N}(\%)$ & $\mathrm{N}(\%)$ & $\mathrm{N}(\%)$ & $\mathrm{N}(\%)$ \\
\hline Pain & $7(100 \%)$ & $2(28.6 \%)$ & $7(100 \%)$ & - \\
\hline $\begin{array}{l}\text { Hand color: } \\
\text { Pallor } \\
\text { Cyanosis }\end{array}$ & $\begin{array}{l}7(100 \%) \\
7(100 \%)\end{array}$ & $\begin{array}{l}- \\
2(28.6 \%)\end{array}$ & $\begin{array}{l}7(100 \%) \\
7(100 \%)\end{array}$ & - \\
\hline Hand coldness & $7(100 \%)$ & $2(28.6 \%)$ & $7(100 \%)$ & - \\
\hline $\begin{array}{l}\text { Distal pulse: } \\
\text { Normal } \\
\text { Weak } \\
\text { No }\end{array}$ & $\begin{array}{l}- \\
1(14.3 \%) \\
6(85.7 \%)\end{array}$ & $\begin{array}{l}4(57.1 \%) \\
1(14.3 \%) \\
2(28.6 \%)\end{array}$ & $\begin{array}{l}- \\
1(14.3 \%) \\
6(85.7 \%)\end{array}$ & $\begin{array}{l}6(85.7 \%) \\
1(14.3 \%) \\
-\end{array}$ \\
\hline $\begin{array}{l}\text { Capillary } \\
\text { Circulation: } \\
\text { Normal } \\
\text { Delayed }\end{array}$ & $\begin{array}{l}- \\
7(100 \%)\end{array}$ & $\begin{array}{l}5(71.4 \%) \\
2(28.6 \%)\end{array}$ & - & $\begin{array}{l}6(85.7 \%) \\
1(14.3 \%)\end{array}$ \\
\hline
\end{tabular}

of the median nerve. ${ }^{26,27}$

Pre-operative duplex evaluation is also not sufficient to establish the diagnosis. Retrograde flow in the brachial artery just distal to the fistula is detected in the majority of patients following proximal access creation, indicating that the access consumes not only the antegrade flow, but also a portion of the collateral flow to the forearm. ${ }^{17}$ However, pre-operative duplex is useful in suspecting proximal or distal arterial lesions as well as for measuring the radial and ulnar arterial diameters before planning the intervention to choose the dominant one for distal anastomosis landing. Moreover, duplex mapping of the great saphenous vein is required in most patients. Post-operatively, duplex is useful in detecting that the reversed flow has stopped by any of either maneuvers (DRIL or RUDI), and that antegrade flow is 
Table 4: Duplex data preoperative and one month postoperative in both groups:

\begin{tabular}{|l|l|l|l|l|}
\hline \multirow{2}{*}{} & \multicolumn{2}{|c|}{ DRIL } & \multicolumn{2}{c|}{ RUDI } \\
\cline { 2 - 5 } & $\begin{array}{c}\text { Pre- } \\
\text { operative }\end{array}$ & $\begin{array}{c}\text { Post- } \\
\text { operative }\end{array}$ & $\begin{array}{c}\text { Pre- } \\
\text { operative }\end{array}$ & $\begin{array}{c}\text { Post- } \\
\text { operative }\end{array}$ \\
\hline Vein diameter mean (mm) & 16.6 & 14 & 16.6 & 11.8 \\
\hline Venous outflow velocity mean (cm/sec) & 266.6 & 219.4 & 212.5 & 110 \\
\hline $\begin{array}{l}\text { Brachial "proximal” artery flow velocity } \\
\text { mean(cm/sec) }\end{array}$ & 154.2 & 183.6 & 217.5 & 297 \\
\hline Distal artery wave pattern & $\begin{array}{l}\text { Improved in 5 cases } \\
(71.4 \%)\end{array}$ & $\begin{array}{l}\text { Improved in 6 cases } \\
(85.7 \%)\end{array}$ \\
\hline
\end{tabular}

well established with good distal perfusion of forearm and hand arteries. Arteriography, whether conventional, CT angiography or magnetic resonance angiography (MRA) of the donor artery may be helpful in the 20 $30 \%$ of patients who have proximal inflow stenosis. In those cases, compression of the AV fistula is an additional maneuver to visualize the impaired distal vessels. ${ }^{17}$

In the present study, the clinical presentation was stage III DASS in $2(28.57 \%)$ cases of each group, and stage IV in the remaining 5 patients $(71.43 \%)$. Stage IV patients presented by either superficial hand ulcers and necrosis which were found in 7 cases; 3 in group (1) and 4 in group (2) or by gangrene of digits that required postoperative amputation which was found in 2 cases in group (1) and one case of group (2). Interval from AVF creation to intervention (DRIL or RUDI) was a mean of 13 months (ranging from 0 to 45 months). This time may be to some extent long and this might be due to delay in diagnosis, exclusion of associated proximal and distal arterial lesions, also not all cases of steal are treated by intervention but only when conservative methods of treatment have failed and stages III or IV have been reached. Haimov et al. ${ }^{20}$ reported three hand amputations and one finger amputation and Redfern et $\mathrm{al}^{28}$ performed six digital amputations due to necrosis. Illig et $\mathrm{al}^{29}$ reported treatment of 9 patients with DRIL, 5 with rest pain (stage III) and 4 with (stage IV) active ulceration or gangrene, two had motor dysfunction. Interval from AVF creation to DRIL was ranging from 0 to 50 months, with a mean of 1 year. Seven DRIL procedures were performed with saphenous vein and two with polytetrafluoroethylene.

Two treatment methods had been used in this current study, DRIL and RUDI each was used for treatment of 7 cases of DASS. In DRIL group symptoms of steal clearly improved in 5 patients $(71.43 \%)$, while 2 patients were still suffering cyanosis and pain especially during dialysis, infection necessitated ligation of the access in one of them and deterioration of the limb with no attempts of healing of ulcers necessitated ligation of the other. Access patency was 5 cases $(71.43 \%)$ and limb salvage was $(100 \%)$ both at 3 months. Ulcer healing occurred in a mean duration of 29 days. Better results were obtained in RUDI group, where all cases had improved, access patency and limb salvage were $(100 \%)$, mean duration of complete ulcer healing was 21 days.

Schanzer et al. in 1988 first described the DRIL procedure. ${ }^{11}$ The same authors later reported their results in 23 patients, noting complete resolution of symptoms in 19 patients, one late amputation, 95.6\% two-year bypass patency, and $73.0 \%$ and $45.5 \%$ one- and two-year fistula patency, respectively. $^{20}$ In a more recent study, Schanzer and Eisenberg treated 42 patients, with $34(83 \%)$ experiencing complete resolution of symptoms. ${ }^{30}$ Berman et al ${ }^{19}$ treated 21 cases with DRIL technique, at one year fistula patency was $94 \%$, while Knox et $\mathrm{al}^{31}$ reported patencies of $83 \%$ at 1 year and $71 \%$ at 3 years in their 52 cases series. Lazaridies et al, ${ }^{17}$ reported access patency 
of $69 \%$ at 1 year, they managed 28 cases 10 native fistulae and $18 \mathrm{AV}$ grafts.

The DRIL procedure involves ligating the native vessel just distal to the AV fistula, with revascularization of the hand via an arterial bypass originating at least $5 \mathrm{~cm}$ proximal to the fistula. The bypass is thought to help correct the discordance in the resistances of the fistula and the distal vascular bed by lengthening the fistula and improving the collateral circulation to the distal vascular bed. ${ }^{32}$ However, the main feature of the procedure is that it directly prevents the reversal of flow in the brachial artery by ligation just distal to the fistula. ${ }^{30}$ The bypass ensures normal flow to the hand via an alternate pathway. DRIL technique restores antegrade flow to the ischemic limb, eliminates the potential pathway for the steal mechanism, and preserves the dialysis access. Ligation of the healthy native (brachial) artery in a relatively ischemic limb is the main drawback of DRIL method, so it leaves the distal arm dependent on a graft for blood supply moreover distal anastomoses are technically more difficult in patients with diffuse diseases in the distal forearm arteries. ${ }^{8}$

Attempts to avoid the main disadvantage of DRIL led Minion et al., in $2005^{8}$ to describe another treatmentmethod for thisclinical entity that maintains the native arterial circulation. RUDI consists of ligating the fistula vein at its origin and re-establishing inflow to the fistula using a more distal arterial source. The source consisted of the proximal radial or ulnar artery approximately 2 to $3 \mathrm{~cm}$ distal to the brachial bifurcation. Minion et $\mathrm{al}^{8}$ in their report revised 4 cases of DASS, the proximal radial artery was used as the supply for the RUDI in two patients and the ulnar artery in the other two. A branch of the cephalic vein was used to reestablish flow in the fistula for two patients, and a segment of the brachial vein was used in a third. These vein segments were of slightly smaller diameter than the venous outflow of the fistulae. The fourth patient underwent basilic vein transposition at the time of RUDI (with direct reanastomosis to the ulnar artery). Three patients reported complete relief of symptoms. The fourth patient had relief of pain but complained of mild residual paraesthesia. Limb salvage and access patency were achieved at last follow up (mean 8 months) in all cases. Corfield et $\mathrm{al}^{33}$ performed 3 cases of RUDI with success in all and fistula patency of $100 \%$. These results are consistent with the current study.

The development of RUDI procedure was encouraged by the use of the proximal radial artery as inflow for primary AV fistulae by Burns and Jennings. 34 The same principle have been used by Ehsan et al, in 2005 in the so called 'extension technique, 35 with an anastomosis formed between proximal radial or ulnar artery, approximately 2-3 $\mathrm{cm}$ below the brachial bifurcation, and the median antecubital vein in primary AV fistula creation. Essentially, the RUDI technique is a conversion to this configuration. This supports the use of the proximal radial (or ulnar) artery for inflow during primary fistula construction when feasible in patients thought to be at high risk for developing steal. The rationale behind this technique is to try to preserve about half of the blood supply to the hand by using one artery beyond the bifurcation. ${ }^{36}$ This can help to prevent steal syndrome.

RUDI both lengthens the fistula and reduces the diameter. Length is added in both the arterial and venous limbs. RUDI thus takes advantage of natural reductions in vessel diameter, in contrast to the artificial extrinsic constriction of banding. Finally, RUDI restores antegrade flow in the brachial artery and therefore should improve the collateral flow to the hand in the remaining branches of the brachial artery. In patients without concomitant arterial occlusive disease and DASS, it may be noted that RUDI may prove superior to DRIL in that it avoids ligation of a normal artery supplying an ischemic hand. ${ }^{8}$

\section{Conclusion:}

RUDI procedure incorporates most of the advantages of other access and handpreserving procedures. By using a smaller distal artery as inflow, it lengthens the fistula, decreases the radius, and preserves antegrade flow in the brachial artery. In contrast to DRIL procedure, it is the fistula that is placed at 
risk by ligation and revascularization, not the native arterial supply to the ischemic hand. We think RUDI may become the procedure of choice for patients with dialysis-associated steal syndrome after a brachial artery-based arteriovenous fistula and no concomitant arterial occlusive disease. Further followup and assessment regarding long-term patency and incidence of recurrence of steal is required also increasing number of patients subjected to the research is essential to obtain satisfactory significant results.

\section{Reference}

1- Mickley V: Steal syndrome - strategies to preserve vascular access and extremity. Nephrol Dial Transplant 2008; 23: 19-24.

2- Konner K, Hulbert-Shearon TE, Roys EC et al. Tailoring the initial vascular access for dialysis patients. Kidney Int 2002; 62: 329-338.

3- Lazarides MK, Staramos DN, Panagopoulos GN et al: Indications for surgical treatment of angioaccess-induced arterial steal. $J$ Am Coll Surg 1998; 187: 422-426.

4- Morsy AH, Kulbaski M, Chen C, Isiklar H, Lumsden AB: Incidence and characteristics of patients with hand ischemia after a hemodialysis access procedure. $J$ Surg Res 1998; 74: 8-10.

5- Odland MD, Kelly PH, Ney AL et al: Management of dialysis associated steal syndrome complicating upper extremity arteriovenous fistulas: Use of intraoperative digital photoplethysmography. Surgery 1991; 110: 664-669.

6- Davidson D, Louridas G, Guzman R, et al: Steal syndrome complicating upper extremity hemoaccess procedures: Incidence and risk factors. Can J Surg 2003; 46: 408-412.

7- DeCaprio JD, Valentine RJ, Kakish HB, Awad R, Hagino RT, Clagett GP: Steal syndrome complicating hemodialysis access. Cardiovasc Surg 1997; 5: 648-653.

8- Minion DJ, Moore E, Endean E: Revision using distal inflow: A novel approach to dialysis-associated steal syndrome. Ann Vasc Surg 2005; 19: 625-628.

9- Yu SH, Cook PR, Canty TG, McGinn RF, Taft PM, Hye RJ: Hemodialysis-related steal syndrome: Predictive factors and response to treatment with the distal revascularization interval ligation procedure. Ann Vasc Surg
2008; 22: 210-214.

10- Zamani P, Kaufman J, Kinlay S: Ischemic steal syndrome following arm arteriovenous fistula for hemodialysis. Vascular Medicine 2009; 14: 371-376.

11- Schanzer H, Schwartz M, Harrington E, Haimov M: Treatment of ischemia due to "steal" by arteriovenous fistula with distal artery ligation and revascularization. $J$ Vasc Surg. 1988; 7: 770-773.

12- Zanow J,KrugerU, ScholzH:Proximalization of the arterial inflow: A new technique to treat access-related ischemia. J Vasc Surg. 2006; 43: 1216-1221 discussion 1221

13- Plumb T J, Lynch Th G, Adelson A B: Treatment of steal syndrome in a distal radiocephalic arteriovenous fistula using intravascular coil embolization. J Vasc Surg 2008, 457-459.

14- Malgor R D, Yoshida R, Sobreira M, Giannini M, Yoshida W, Almeida H: Distal revascularization and interval ligation for the treatment of steal syndrome secondary to hemodialysis arteriovenous fistula in the lower limb. J Vasc Bras 2007; 6(3): 288-92.

15- Storey BG, George CR, Stewart, JH, Tiller DJ, May J, Sheil AG: Embolic and ischemic complications after anastomosis of radial artery to cephalic vein. Surgery 1969; 66: 325-327.

16- Sivanesan S, Bakran A, How T: Characterising flow distributions in $\mathrm{AV}$ fistulae for haemodialysis access. Nephrol Dial Transplant 1998; 13: 3108-3110.

17- Lazarides M, Staramos D, Kopadis G, Maltezos C, Tzilalis V, Georgiadis G: Onset of arterial 'steal' following proximal angioaccess: Immediate and delayed types. Nephrol Dial Transplant 2003; 18: 2387-2390.

18- Wixon CL, Hughes JD, Mills JL: Understanding strategies for the treatment of ischemic steal syndrome after hemodialysis access. J Am Coll Surg 2000; 191: 301-310.

19- Berman S, Gentile A T, Glickman M H, Mills J L, Westerband A, Marek J M: Distal revascularization-interval ligation for limb salvage and maintenance of dialysis access in ischemic steal syndrome. $J$ Vasc Surg 1997; 26: 393-404.

20- Haimov M, Schanzer H, Skladani M: Pathogenesis and management of upper extremity ischemia following angioaccess surgery. Blood Purif 1996; 14: 350-354.

21- Lin G, Kals H, Halpern Z, et al: Pulse 
oxymetry evaluation of oxygen saturation in the upper extremity with an arterio- venous fistula before and during hemodialysis. Am J Kidney Dis 1997; 2: 230-232.

22- Jendrisak MD, Anderson CB: Vascular access in patients with arterial insufficiency. Ann Surg 1990; 212: 187-193.

23- Piotrowski JJ, Alexander JJ, Yuhas JP: Vascular steal in hemodialysis: still unpredictable. Vasc Surg 1996; 30: 289-292.

24- Furhman TM, McSweeney E: Noninvasive evaluation of collateral circulation to the hand. Acad Emer Med 1995; 2: 195-199.

25- Goff CD, Sato DT, Bloch PH, et al: Steal syndrome complicating hemodialysis access procedures: Can it be predicted? Ann Vasc Surg 2000; 14: 138-144.

26- Sessa C, Riehl G, Porcu P, Pichot O, Palacin $\mathrm{P}$, Maghlaoua $\mathrm{M}$ et al: Treatment of hand ischemia following angioaccess surgery using the distal revascularization intervalligation technique with preservation of vascular access: Description of an 18-Case Series. Ann Vasc Surg 2004; 18: 685-694.

27- Sessa C, Pecher M, Maurizi-Balzan J, et al: Critical hand ischemia after angioaccess surgery: Diagnosis and treatment. Ann Vasc Surg 2000;14: 585-593.

28- Redfern AB, Zimmermann NB, Baltimore MD: Neurologic, ischemic complications of upper extremity vascular access for dialysis. J Hand Surg 1995; 20A: 199-204.

29- Illig KA, Surowiec S, Shortell CK, Davies MG, Rhodes JM, Green RM: Hemodynamics of distal revascularization-interval ligation. Ann Vasc Surg 2005; 19: 199-207.

30- Schanzer H, Eisenberg D: Management of steal syndrome resulting from dialysis access. Semin Vasc Surg 2004;17: 45-49.

31- Knox RC, Berman SS, Hughes JD, Gentile AT, Mills JL: Distal revascularization interval ligation: A durable and effective treatment for ischemic steal syndrome after hemodialysis access. J Vasc Surg 2002; 36(2): 250-255.

32- Wixon CL, Mills JL, Berman SS: Distal revascularization interval ligation for maintenance of dialysis access and restoration of distal perfusion in ischemic steal syndrome. Semin Vasc Surg 2000; 13: 77-82.

33- Corfield L, Muller J, Ryan J, Bond R: Distalization of the Anastomosis: An Effective Treatment for dialysis accessassociated steal syndrome. Ann Vasc Surg 2012; 572: 11-13.

34- Bruns SD, Jennings WC: Proximal radial artery as inflow site for native arteriovenous fistula. J Am Coll Surg 2003; 197: 58-63.

35- Ehsan O, Bhattacharya D, Darwish A, Al-khaffaf $\mathrm{H}$ : 'Extension Technique': A modified technique for brachio-cephalic fistula to prevent dialysis access-associated steal syndrome. Eur J Vasc Endovasc Surg 2005; 29: 324-327.

36- Tonks AM, Lawrence J, Lovie MJ: Comparison of ulnar and radial arterial blood-flow at the wrist. J Hand Surg [Br] 1995; 20(2): 240-242. 